\title{
Prospective Uses of Genetically Engineered Lactic Acid Bacteria for the Prevention of Inflammatory Bowel Diseases
}

\author{
Jean Guy LeBlanc ${ }^{1}$, Silvina del Carmen ${ }^{1}$, Fernanda Alvarenga Lima², \\ Meritxell Zurita Turk2, Anderson Miyoshi2, \\ Vasco Azevedo ${ }^{2}$ and Alejandra de Moreno de LeBlanc ${ }^{1}$ \\ ${ }^{1}$ Centro de Referencia para Lactobacilos (CERELA-CONICET), \\ San Miguel de Tucumán, Tucumán, \\ ${ }^{2}$ Institute of Biological Sciences, Federal University of Minas Gerais (UFMG-ICB), \\ Belo Horizonte, MG, \\ ${ }^{1}$ Argentina \\ ${ }^{2}$ Brazil
}

\section{Introduction}

Inflammatory bowel disease (IBD) is a term used to describe a group of intestinal disorders in which inflammation is a major feature. Although rare forms of IBD exist, these diseases normally pertain to ulcerative colitis (UC) (Head \& Jurenka, 2003) and Crohn's disease (CD) (Baumgart \& Sandborn, 2007). There is evidence that these do not represent distinct conditions but rather are the same disease with shared etiological factors (Price, 1992); however, clinical manifestations (such as the exact location of the pathology or the affected individual's immunological and constitutional endowment) are distinctive between both.

Despite many years of study, the exact etiology and pathogenesis of these disorders remain unclear but great advances have been made using experimental animal models and have provided insights into the complex, multi-factorial processes and mechanisms that can result in chronic intestinal inflammation (Elson \& Weaver, 2003).

The aim of this chapter is to present an overview of the current expanding knowledge of the mechanisms by which lactic acid bacteria and other probiotic microorganisms participate in the prevention and treatment of IBD and how genetic engineering techniques can be used to improve their effectiveness or create novel therapeutic strains. In the following sections, the mechanisms by which these beneficial microorganisms exert their therapeutic effects, which include changes in the gut microbiota, stimulation of the host immune responses, enhancement of intestinal barrier function and reduction of the oxidative stress due to their antioxidant properties will be discussed.

\section{Lactic acid bacteria and inflammatory bowel diseases}

Lactic acid bacteria (LAB) constitute a phylogenetically heterogeneous group of ubiquitous microorganisms that are naturally present in high nutrient containing organic products such 
as foods and occupy a wide range of ecological niches ranging from the surface of plants to the gastro-urogenital tract of animals. Currently, the LAB group includes a large number of cocci and bacilli, such as species of the genera Carnobacterium, Enterococcus, Lactobacillus, Lactococcus, Leuconostoc, Oenococcus, Pediococcus, Streptococcus, Tetragenococcus, Vagococcus and Weissella, that normally contain a G+C content inferior to $55 \%$ in their chromosomal DNA. Although quite diverse, the members of this group have various characteristics in common, that include being: (i) Gram-positive; (ii) facultative anaerobes; (iii) nonsporulating; (iv) non-motile and (v) possess the capacity to convert sugars into lactic acid (Nouaille et al., 2003). LAB are one of the most important industrial groups of bacteria that are widely used in food production, health improvement and production of macromolecules, enzymes and metabolites.

From a historical point of view, LAB have been used since ancient times in food fermentation processes and preservation. Since the 1980's, many efforts have been made to better understand the molecular basis of LAB's technological properties in order to control the industrial processes involving these important microorganisms. Due to their lack of pathogenicity, most LAB species have received the GRAS (Generally Recognized As Safe) status by the U.S. Food and Drug Administration. In addition to their important technological properties in food production (production of lactic acid, decrease of lactose, improvement of organoleptic and physical characteristics), various species of LAB, such as Lactobacillus casei, Lactobacillus delbrueckii, Lactobacillus acidophilus, Lactobacillus plantarum, Lactobacillus fermentum and Lactobacillus reuteri, have been shown to possess therapeutic properties since they are able to prevent the development of some diseases as shown mostly using animal models and have the capacity to promote beneficial effects in human and animal health (LeBlanc et al., 2008). Because of all of their documented beneficial effects, certain strains of LAB have been designated as being probiotic that have been defined by the $\mathrm{FAO} / \mathrm{WHO}$ as "live microorganisms which when administered in adequate amounts confer a health benefit on the host" (FAO/WHO, 2001). Some of the health benefits which have been claimed for probiotics include: improvement of the normal microbiota, prevention of infectious diseases and food allergies, reduction of serum cholesterol, anticarcinogenic activity, stabilization of the gut mucosal barrier, immune adjuvant properties, alleviation of intestinal bowel disease symptoms, and improvement of the digestion of lactose in intolerant hosts (Galdeano et al., 2007). The most commonly used strains as probiotics are members of lactobacilli, enterococci and bifidobacteria groups (Ouwehand et al., 2002). Currently, many products containing probiotics are available on retail shelves throughout the world because of the increase consumer demand for healthier natural foods that can increase their overall well-being (Galdeano et al., 2007). The specific health effects of selected probiotic strains have been confirmed by well documented double blind controlled human clinical trials and are becoming increasingly accepted. However, many proposed beneficial effects of probiotics still need further research and more information about their mechanisms of action is needed in order to confirm that they can be useful in the prevention and treatment of other specific diseases (Ouwehand et al., 2002).

\subsection{Mechanisms of action of LAB against IBD}

It has been shown that $\mathrm{LAB}$ and other probiotic microorganims can counteract inflammatory processes in the gut by stabilizing the microbial environment and the permeability of the intestinal barrier, and by enhancing the degradation of enteral antigens 
and altering their immunogenicity (Isolauri et al., 2004). Some of these disease preventing effects have been recently reviewed (del Carmen et al., 2011); however, a few examples of each of the mechanisms by which LAB exert anti-IBD effects will be given to demonstrate their potential uses.

\subsubsection{Modulation of the gut microbiota}

The first mechanism that LAB use to prevent IBD is the modulation of the gastrointestinal microbiota of animals. It was reported that Lactobacillus (L.) reuteri could be used to prevent colitis in IL-10 knock-out (KO) mice by increasing the number of LAB in the gastrointestinal tract (Madsen et al., 1999). Neonatal mice presented a decreased concentration of colonic Lactobacillus species and an increased concentration of mucosal adherent bacteria. Oral administration of the prebiotic lactulose increased the levels of Lactobacillus species and rectal swabbing with $L$. reuteri restored Lactobacillus levels to normal and reduced the number of adherent bacteria within the colon. These effects were associated with the attenuation of UC (Madsen et al., 1999). In a placebo-controlled trial, orally administered $L$. salivarius UCC118 reduced prevalence of colon cancer and mucosal inflammatory activity in IL-10 KO mice by modifying the intestinal microbiota in these animals: Clostridim (C.) perfringens, coliforms, and enterococcus levels were significantly reduced in the probiotic fed group (O'Mahony et al., 2001).

Gut microbiota can antagonize pathogenic bacteria by conferring a physiologically restrictive environment inhibiting bacterial adherence and translocation. Probiotic bacteria also decrease luminal $\mathrm{pH}$, as has been demonstrated in patients with $\mathrm{UC}$ following ingestion of the probiotic preparation VSL\#3, a mixture of 4 lactobacilli strains (L. plantarum, L. casei, L. acidophilus, and L. delbrueckii ssp. bulgaricus), 3 bifidobacteria strains (Bifidobacterium (B.) infantis, B. breve, and B. longum), and 1 strain of Streptococcus (S.) salivarius ssp. thermophilus (Venturi et al., 1999).

Another mechanism by which probiotics can exert a positive effect by inhibiting pathogenic microorganisms is by producing antimicrobial substances such as bacteriocins. Several bacteriocins produced by different Lactobacillus species have been described (Klaenhammer, 1988). The inhibitory activity of these bacteriocins varies; for example, the probiotic $L$. salivarius UCC118 produces a peptide that inhibits a broad range of pathogens such as Bacillus, Staphylococcus, Enterococcus, Listeria, and Salmonella species (Flynn et al., 2002). Lacticin 3147, a broad-spectrum bacteriocin produced by a Lactococcus (Lc.) lactis strain, inhibits a range of genetically distinct $C$. difficile isolated from healthy subjects, patients with IBD and from different origins (Rea et al., 2007).

The Symbiotic Instant Mixture (SIM) containing a prebiotic compound inulin, and a combination of probiotic microorganisms (L. acidophilus La-5 and B. lactis Bb-12) significantly reduced inflammation in transgenic rats that produce human HLA-B27- $\beta 2-$ microglobulin. The effect was enhanced by combination with metronidazole, suggesting a synergistic effect of the combination of antibiotics and probiotics in the treatment of experimental colitis (Schultz et al., 2004). In a double-blind randomized study, the efficacy of VSL\#3 combined with antibiotic treatment on the post-operative recurrence of CD was compared with treatment with mesalazine alone. Combination of antibiotic and probiotic treatment was more efficient in prophylaxis of post-operative recurrence of Crohn's disease (Campieri et al., 2000). 


\subsubsection{Modulation of the host immune responses and enhancement of intestinal barrier function}

The intestinal mucosa is the body's first line of defense against pathogenic and toxic invasions from food. After ingestion, orally administered antigens encounter the GALT (Gut Associated Lymphoid Tissue), which is a well-organized immune network that protects the host from pathogens and prevents ingested proteins from hyperstimulating the immune response through a mechanism called oral tolerance (Weiner et al., 1997).

The main mechanism of protection given by the GALT is humoral immune response mediated by secretory IgA (s-IgA) which prevents the entry of potentially harmful antigens, while also interacting with mucosal pathogens without potentiating damage. The stimulation of this immune response could thus be used to prevent certain infectious diseases that enter the host through the oral route. An increasing number of probiotic strains have shown to highly increase s-IgA, therefore the stimulation of IgA-producing cells is often considered a must in probiotic screening trials (O'Sullivan, 2001).

Numerous studies have shown that certain strains of lactobacilli and bifidobacteria can modulate the production of cytokines (mediators produced by immune cells) that are involved in the regulation, activation, growth, and differentiation of immune cells and have been recently reviewed (de Moreno de LeBlanc et al., 2011). These probiotic microorganisms are able to prevent and treat certain inflammatory diseases in the gastrointestinal tract through the repression of pro-inflammatory cytokines. In this sense, the anti-inflammatory effect of yoghurt administration to mice was studied using a TNBS induced acute intestinal inflammation model. The animals that received yoghurt continuously (before and after TNBS) had lower intestinal damages and improved anti-inflammatory response in the gut (de Moreno de LeBlanc et al., 2009). This improvement of the immune response was related with beneficial changes in the intestinal microbiota and differences in the cytokine production and secretion with increases of IL-10 and decreases of IL-17 in the mice given yoghurt. The same yoghurt was analyzed in a mouse model of recurrent inflammation where the administration of the fermented product after the acute episode, when the animals were recovered, prevented the recurrence of the inflammation (Chaves et al., 2011). One of the central transcription factors mediating inflammatory responses is the nuclear factor $\kappa B(\mathrm{NF}-\kappa \mathrm{B})$. NF- $\kappa \mathrm{B}$ is required for the transcriptional activation of a number of inflammatory effectors, including IL-8, TNF- $\alpha$, IL-6, Cox2, iNOS and many others and, its deregulation has been detected in many inflammatory conditions. It was shown that a number of LABs can suppress inflammatory signals mediated by NF- $\kappa B$. These include strains of the phylogenetically closely related species L. acidophilus and L. johnsonii, which have been isolated from the human GI tract and form part of the acidophilus complex.

One of the ways by which probiotics can exert immunomodulatory activities is by increasing IL-10 production that can in turn help in preventing certain IBD that are caused by abnormal inflammatory responses (de Moreno de LeBlanc et al., 2011). However, not all probiotic strains act in the same manner. Anti-inflammatory effects, such as stimulation of IL-10 producing cells, are strain dependent traits, and their effectiveness also depends on the concentrations used and the method of administration. By increasing IL-10 levels and in consequence decreasing inflammatory cytokines such as TNF- $a$, IFN- $\gamma$, and IL-17 some LAB can prevent the appearance of local inflammatory diseases and could be used as an adjunct therapy with conventional treatments (de Moreno de LeBlanc et al., 2011).

Enhancement of intestinal barrier function is another mechanism by which probiotic bacteria may benefit the host. The exact mechanisms by which probiotic bacteria enhance 
gut mucosal barrier function are unclear, but may relate to alterations in mucus or chloride secretion or changes in mucosal cell-cell interactions and celular stability through modulation of cytoeskeletal and tight junction protein phosphorilation (Hilsden et al., 1996, Madsen et al., 2001, Meddings, 2008, Ng et al., 2009, Schmitz et al., 1999).

Oral treatment with VSL\#3 normalized colonic physiologic function and barrier integrity in IL-10 KO mice as assessed by short circuit currents, transepithelial potential differences, and mannitol fluxes in excised tissues from mice (Madsen et al., 2001).

L. plantarum and L. reuteri enhanced barrier function on a methotrexate-induced enterocolitis rat model (Mao et al., 1996); and colonization of healthy mice intestinal loops with L. brevis reduced intestinal permeability (Garcia-Lafuente et al., 2001).

Some probiotic bacteria modify MUC gene expression and mucus secretion. For example, $L$. plantarum 299v induced intestinal mucin gene (MUC2 and MUC3) expression in vitro (Mack et al., 1999). VSL\#3 also induced expression of mucins in vitro and increased transepithelial resistance (TER), prevented pathogen-induced decrease in TER, and stabilized tight junctions. In this way, probiotics and protein(s) released by these organisms may functionally modulate the intestinal epithelium of the host by different mechanisms, including the competition of whole organisms for contact with the epithelial surface as well as stabilization of the cytoskeleton and barrier function and the induction of mucin expression (Otte \& Podolsky, 2004).

\subsubsection{Reduction of the oxidative stress}

As a result of recurrent and abnormal inflammation, IBD appears to be associated with oxidative stress, which is characterized by an uncontrolled increase in reactive oxygen species (ROS) concentrations in the gastrointestinal tract. Several studies have established a correlation between the increase in ROS production and disease activity in inflamed biopsies of IBD patients. Therefore, a suggested mechanism by which LAB could prevent inflammation is through the expression of antioxidant enzymes that are able to decrease ROS levels or at least impair their formation.

ROS are normal byproducts of oxygen metabolism (such as superoxide ions, free radicals and peroxides). These small molecules can be generated in aerobiosis by flavoproteins and by phagocytes during inflammatory reactions. At low concentrations, ROS participate in cell signaling and regulatory pathways. However, when present in large amounts, they act to eliminate infectious agents by causing significant damages to cell structures and macromolecular constituents such as DNA, RNA, proteins and lipids. When ROS concentration exceeds the capacity of cell defense systems, toxicity is triggered. It is well known that oxidative damage occurs during the pathogenesis of cancer, cirrhosis, atherosclerosis and other chronic diseases. It has been shown for example that human tumor cells produce and excrete large amounts of $\mathrm{H}_{2} \mathrm{O}_{2}$ that might participate in tumor invasion and proliferation (Szatrowski \& Nathan, 1991). Thus, oxidative stress plays an important role in pathologies of the gastrointestinal tract of humans such as IBD as well as in certain types of cancers.

In order to offset oxidative stress, aerobic cells like those of the normal intestinal mucosa are equipped with a complex antioxidant defense system which includes enzymatic and nonenzymatic components having synergistic and interdependent effects on each other. The normal intestinal mucosa is equipped with a network of antioxidant enzymes such as catalase (Cat), glutathione peroxidase (GSH-Px), glutathione reductase (GR), glutathione-stransferase (GST), and superoxide dismutase (SOD) that are able to neutralize ROS. The 
activities of these enzymes are usually balanced to maintain a low and continual steadystate level of ROS; however, the levels of these enzymes are frequently depleted in IBD patients (Kruidenier et al., 2003). Probiotic LAB strains expressing high levels of antioxidant enzymes could increase these enzymatic activities in specific locations of the gastrointestinal tract and could thus contribute to prevent oxidative epithelial damages, giving rise to potential applications for IBD treatment or post-cancer drug treatments. Since few microorganisms produce antioxidant enzymes at the required concentrations to exert biological effects, genetic engineering strategies have been employed to produce antioxidant producing LAB, these will be discussed in another section of this chapter.

Superoxide dismutase (SOD) is considered as the first line of defense against ROS and is a member of the family of metalloenzymes that catalyze the oxido-reduction of superoxide anion to $\mathrm{H}_{2} \mathrm{O}_{2}$. There are three different forms of this enzyme according to their metal center: manganese, copper-zinc, or iron. These enzymes are found across a broad range of organisms, which can use one, two, or all three enzymes to meet their antioxidant needs. In most Streptococcus and Lactococcus spp., elimination of ROS is accomplished through the action of Mn-SOD (Sanders et al., 1995). It has also been reported that two strains of $L$. fermentum, named E-3 and E-18, and a strain of S. thermophilus showed significant antioxidative activity due to production of Mn-SOD (Kullisaar et al., 2002). Furthermore, recent experimental data indicate that subcutaneous treatment with SOD significantly reduces peroxidation reactions in the inflamed colon and confers significant amelioration of colonic inflammatory changes in a rat model of TNBS colitis (Segui et al., 2004). In addition, treatment with SOD decreases oxidative stress and adhesion molecule upregulation in response to abdominal irradiation in mice.

Catalase is another major antioxidant enzyme that catalyzes the decomposition of hydrogen peroxide into water and oxygen. Catalases are widespread in aerobic (facultative or not) bacteria such as E. coli and Bacillus (B.) subtilis (Rochat et al., 2005). There are two different classes of catalases according to their active-site composition: one is heme-dependent and the other, also named pseudocatalase is manganese-dependent. By definition, LAB are catalase negative microorganisms, thus genetic modifications are necessary in order for them to produce this important antioxidant enzyme.

\section{Genetics of $L A B$ and recombinant protein production strategies}

Comparative genomics has facilitated our understanding of LAB evolution and has indicated that a combination of gene gain and loss occurred during the evolution of these bacteria in various environmental habitats (Makarova et al., 2006). Beginning with the genome sequencing of Lc. lactis IL-1403 in 1999 (Bolotin et al., 1999), by July 2011 there were $314 \mathrm{LAB}$ genomes (98 complete and 216 in progress) publicly available at the National Center for Biotechnology Information (NCBI, 2011).

Lc. lactis is widely used in the dairy industry and is normally used as the model for other $\mathrm{LAB}$, not only because of its economic importance, but also because of the following features: (1) it has a completely sequenced genome; (2) it is genetically easy to manipulate; and (3) many genetic tools have already been developed for this species.

Studies based on the identification and isolation of wild-type plasmids from L. lactis and other LAB have made it possible to develop various cloning vectors. Using molecular biology techniques, these plasmids have been manipulated so that they have become important tools for cloning and studying genes of interest, both those of prokaryotes and 
eukaryotes. They basically consist of (1) origin of replication (ori), (2) selection marker (gene) for antibiotic resistance, and (3) multiple-cloning site.

The expression of heterologous proteins in Lc. lactis has been favored both by advances in genetic knowledge and by new developments in molecular biology techniques. Using this duet of tools to obtain increased levels of these proteins and control their production, various vectors containing constitutive or inductive promoters were developed and currently constitute the basis of all expression systems in Lc. lactis and other LAB.

\subsection{LAB expression systems}

LAB are potential candidates to be used as vehicles for the production and delivery of heterologous proteins of vaccinal, medical, or technological interest and various delivery systems are now available for these probiotic microorganisms (Miyoshi et al., 2010). Different genetic engineering strategies in LAB have been used to: improve their carbohydrate fermenting properties (lactose, galactose), increase specific metabolite production (diaceyl, acetoin), produce or increase enzymatic activities (proteolytic enzymes, $\alpha$ - and $\beta$-galactosidase, $\alpha$-amylase), or conferring them the capacity to produce beneficial compounds such as bacteriocins, exopolysaccharide (EPS) and other sugars, vitamins, antioxidant enzymes and anti-inflammatory cytokines (Sybesma et al., 2006).

A series of studies to develop new strains and efficient expression systems has been conducted to use LAB as "cell factories" for the production of proteins (Djordjevic \& Klaenhammer, 1998). However, in order for some of these proteins (enzymes and antigens) produced by bacteria to attain the desired biological activity levels, it is necessary that they correctly target specific cellular locations: (1) cytoplasm, (2) membrane, or (3) extracellular environment.

\subsubsection{Nisin-Controlled Expression (NICE) system}

A versatile and tightly controlled gene expression system was first described in 1995, based on the auto-regulation mechanism of the bacteriocin nisin, denominated the NisinControlled Expression (NICE) system (Kuipers et al., 1995). This system has become one of the most successful and widely used tools for regulated gene expression in Gram-positive bacteria. An extensive overview of the different applications in lactococci and other Grampositive bacteria has been published 10 years after the NICE system was first published (Mierau \& Kleerebezem, 2005) showing its potential use in: (1) over-expression of homologous and heterologous genes for functional studies and to obtain large quantities of specific gene products, (2) metabolic engineering, (3) expression of prokaryotic and eukaryotic membrane proteins, (4) protein secretion and anchoring in the cell envelope, (5) expression of genes with toxic products and analysis of essential genes and (6) large scale applications.

\subsubsection{Xylose-Inducible Expression System (XIES)}

Another controlled production system to target heterologous proteins to cytoplasm or extracellular medium was described for Lc. lactis NCDO2118 based on the use of a xyloseinducible lactococcal promoter, PxylT (Miyoshi et al., 2004). The capacities of the XyloseInducible Expression System (XIES) to produce cytoplasmic and secreted proteins were tested using the Staphylococcus aureus nuclease gene $(n u c)$ fused or not to the lactococcal Usp45 signal peptide. Xylose-inducible gene expression is tightly controlled and resulted in 
high-level and long-term protein production, and correct targeting either to the cytoplasm or to the extracellular medium. Furthermore, this expression system is versatile and can be switched on or off easily by adding either xylose or glucose, respectively, and has potential as an alternative and useful tool for the production of proteins of interest in Lc. lactis.

\subsection{3 pValac}

A new plasmid vector for DNA delivery using lactococci, the pValac plasmid was constructed by the fusion of: i) an eukaryotic region, allowing the cloning of an antigen of interest under the control of the pCMV eukaryotic promoter to be expressed by a host cell and ii) a prokaryotic region allowing replication and selection of bacteria (Guimaraes et al., 2009). In order to evaluate pValac functionality, the $g f p$ ORF was cloned into pValac (pValac: $g f p$ ) and was analyzed by transfection in PK15 cells. Invasiveness assays of Lc. lactis inlA+ strains harbouring pValac:gfp into Caco-2 cells demonstrated the potential of pValac to deliver DNA and trigger DNA expression by epithelial cells.

\section{Prevention of IBD using genetically modified LAB}

As described above, LAB are potential candidates to be used as vehicles for the production and delivery of heterologous proteins of vaccinal, medical, or technological interest and various delivery systems are now available for these probiotic microorganisms (Miyoshi et al., 2010). The use of LAB that produce anti-inflammatory compounds (such as IL-10 and antioxidant enzymes) in the treatment of colitis and IBD will be discussed in the following sections.

\subsection{Antioxidant enzyme producing strains}

As stated earlier, in IBD patients, oxidative stress occurs as a result of recurrent and abnormal inflammation with an associated increase in ROS concentrations.

Since few microorganisms produce antioxidant enzymes at concentrations required to exert biological effects, genetic engineering strategies have been employed to produce antioxidant producing $\mathrm{LAB}$. Recent reviews have shown the potential uses of such strains in the treatment of IBD using a variety of animal models (Spyropoulos et al., 2010). LAB have been used to locally deliver antioxidant enzymes (such as SOD) directly to the intestines, an important breakthrough since oral administration of SOD is greatly limited by its short lifespan (5-10 $\mathrm{min}$ ) in the hostile conditions of the gastrointestinal tract. It has been shown that genetically engineered L. plantarum and Lc. lactis capable of producing and releasing SOD exhibit anti-inflammatory effects in a TNBS colitis model (Han et al., 2006). Another experimental study demonstrated that L. gasseri producing manganese SOD had significant anti-inflammatory activity reducing the severity of colitis in IL-10-deficient mice (Carroll et al., 2007). Recent data has shown that SOD producing L. casei BL23 was able to significantly attenuate the TNBS-induced damages as shown by higher survival rates, decreased animal weight loss, lower bacterial translocation to the liver and the prevention of damage to the large intestines (LeBlanc et al., 2011). This is in agreement with previous results that have shown that the same SOD-expressing strain of L. casei was able to slightly attenuate the colonic histological damage score of a DSS-induced colitis model (Watterlot et al., 2010).

Since Lc. lactis has no catalase (as is also the case for the majority of LAB), the B. subtilis heme catalase Kat E gene was introduced into this industrially important microorganism 
giving rise to a strain capable of producing active catalase that can provide efficient antioxidant activity (Rochat et al., 2005). Recently, the heterologous expression of non-heme catalase in bacteria relevant to dairy industries (L. casei) has also been reported (Rochat et al., 2006). This latter strain offers the advantage that no exogenous heme has to be added to the culture medium in order to exert an efficient catalase activity. We have previously shown that the catalase-producing Lc. lactis strain was able to prevent tumor appearance in the colon (de Moreno de LeBlanc et al., 2008). In another study, we have shown that a catalase producing strain of $L$. casei BL23 significantly decreased the physiological damages caused by the TNBS administration (LeBlanc et al., 2011). This result is similar to those obtained previously where it was shown that both the native strain of L. casei BL23 and its catalase producing derivative presented a significant reduction of caecal and colonic inflammatory scores (Rochat et al., 2007).

\subsection{IL-10 producing strains}

Genetically modified Lc. lactis secreting IL-10 provides a novel therapeutic approach for IBD. The first description of Lc. lactis that can secrete biologically active IL-10 was published in 2000 (Schotte et al., 2000). In this pioneer study, murine- IL-10 was synthesized as a fusion protein, consisting of the mature part of the eukaryotic protein fused to the secretion signal of the lactococcal Usp45 protein. Intragastric administration of this recombinant Lc. lactis strain prevented the onset of colitis in IL-10 KO mice and caused a $50 \%$ reduction of the inflammation in DSS -induced chronic colitis (Steidler et al., 2000).

The application of IL-10 producing LAB is not only limited to the treatment of IBD. It was recently shown that treatment of asthma with a Lc. lactis expressing murine IL-10 was efficient since this LAB modulated experimental airway inflammation in the mouse model (Marinho et al., 2010). Lc. lactis producing recombinant IL-10 used in this study was efficient in suppressing lung inflammation, independently of Treg cells, since this cytokine plays a central role in the regulation of inflammatory cascades, allergen-induced airway inflammation and non-specific airway responsiveness (Tournoy et al., 2000). In another study, it was shown that oral administration of an IL-10-secreting Lc. lactis strain could prevent food-induced IgE sensitization in a mouse model of food allergy (Frossard et al., 2007). These studies confirm that IL-10 secreting LAB hold potential for the treatment of many inflammatory diseases where this cytokine acts as a modulating compound.

Although a clear positive effect of these recombinant strains has been demonstrated, the exact mechanism by which the beneficial effect of the IL-10-producing Lc. lactis on the mucosa is produced remains unclear. A recent study has demonstrated the uptake of IL-10secreting Lc. lactis by the paracellular route in inflamed mucosal tissue in mouse models of chronic colitis, suggesting that IL-10 production by these LAB residing inside the mucosa in the vicinity of responsive cells can improve the local action of IL-10 in inflamed tissue and the efficiency of the treatment (Waeytens et al., 2008). In another study, it was shown that genetically engineered Lc. lactis secreting murine IL-10 could modulate the functions of bone marrow-derived DC in the presence of LPS (Loos et al., 2009). This data suggest that the beneficial effects of IL-10 secreting LAB during chronic colitis might involve inhibition of CD4+ Th17 cells and a reduced accumulation of these cells as well as other immune cells at the site of inflammation.

In another study, we have evaluate the anti-inflammatory effect of the administration of milks fermented by Lc. lactis strains that produce IL-10 under the control of the XIES, using a Trinitrobenzenesulfonic acid induced colitis murine model. Mice that received milks 
fermented by Lc. lactis strains producing IL-10 in the cytoplasm (Cyt strain) or secreted to the product (Sec strain) showed lower damage scores in their large intestines, decreased IFN-ץ levels in their intestinal fluids and lower microbial translocation to liver, compared to mice receiving milk fermented by the wild-type (Wt) strain or those not receiving any treatment (unpublished data). The results obtained in this study show that the employment of fermented milks as a new form of administration of IL-10 producing L. lactis is effective in the prevention of IBD in a murine model. This new approach could lead to the development of novel fermented products with therapeutical purposes; suitable for specific populations suffering from gastrointestinal disorders or prone to acquiring them. Similar strains could also be included in probiotic mixtures together with other strains that are able to prevent inflammation by other mechanisms such as immune stimulation or that possess antioxidant properties.

\section{Prospective uses of GM-LAB}

Although there is no scientific evidence that supports the notion that genetically modified (GM) foods or microorganisms are dangerous for human consumption, it is necessary to demonstrate that these are innocuous in order to alleviate the fears held by the general public associated with the use of genetically modified organisms, if we want to use designer probiotics to extend the range of applications covered by natural probiotics. Also, the proper design of GM-LAB is essential in order to eliminate the risks of dissipation in the environment and prevent the transfer of certain genes (such as antibiotic resistance genes) to other microorganisms.

The construction of a biological containment system for a genetically modified Lc. lactis for intestinal delivery of human IL-10 is an important step forward for the safe use of GM-LAB for human therapeutic purposes (Steidler et al., 2003). In this study, the thymidylate synthase gene of Lc. lactis was replaced by the human IL-10 gene, making this strain incapable of growing when deprived of thymidine or thymine. This strain does not contain any antibiotic resistance markers and because of its thymidine auxotrophy, it cannot disseminate in the environment making it one of the safest GM strains ever engineered. This containment system was recently evaluated in CD patients and it was shown that no adverse effects were produced after consuming this GM-LAB and that it could only be recovered in feces when thymidine was added (Braat et al., 2006). Although only preliminary results from this phase 1 trial were obtained, the use of genetically modified bacteria for mucosal delivery of proteins is a feasible strategy in human with chronic intestinal inflammation (Braat et al., 2006).

Intragastric administration of Lc. lactis genetically modified to secrete IL-10 in situ in the intestine was shown to be effective in healing and preventing chronic colitis in mice. However, its use in humans is hindered by the sensitivity of Lc. lactis to freeze-drying and its poor survival in the gastrointestinal tract, reasons for which novel means for more effective mucosal delivery of therapeutic LAB are currently being developed (Huyghebaert et al., 2005a, b, Termont et al., 2006).

\section{Conclusion}

This review has shown that probiotics have been extensively used in order to prevent and treat inflammatory bowel diseases. The mechanism of action of these beneficial 
microorganisms, which includes changes in the gut microbiota, stimulation of the host immune responses, enhancement of intestinal barrier function and reduction of the oxidative stress due to their antioxidant properties and antioxidant enzyme production has been demonstrated principally using animal models and in specific human trials. It has recently been suggested that there is a lack of well-designed, large, randomized, placebocontrolled trials that can certify that probiotics are effective in the prevention and treatment of IBD (Mallon et al., 2007). Additional studies such as the double-blind, randomized, placebo-controlled clinical trial of the treatment of relapsing mild-to-moderate ulcerative colitis with the probiotic VSL\#3 as adjunctive to a standard pharmaceutical treatment (Tursi et al., 2010) are required to confirm animal data and are necessary to convince the medical and general community of the benefits and potential application of probiotics in the prevention and treatment of IBD.

Although probiotic effects are a strain dependent trait, using modern genetic engineering techniques it is theoretically possible to obtain strains that can exert a variety of beneficial properties. For example, the introduction of antioxidant enzyme genes or cytokine producing capabilities in current probiotic strains that have natural anti-inflammatory properties, such as the ability to modulate the immune dependant anti-inflammatory processes, could generate very useful strains that could be applied in the treatment of a variety of inflammatory diseases. These strains could also be included in treatment protocols since it has been shown that probiotics can enhance the effectiveness of traditional IBD treatments. However, before proposing the genetic modification of anti-inflammatory strains, the innate mechanisms of the potential host strains should be demonstrated in properly designed large scale human clinical trials. These trials are essential in future studies using the engineered strains to demonstrate the differences between the native and modified microorganisms.

The consumption of engineered strains by humans is still highly controversial due to the public perception that genetic manipulation is not "natural". Scientists must perform welldesigned studies where the results are divulged to the general populations in order to inform consumers of the obvious beneficial effects these novel techniques can confer with the minimum of risk to their health and to the environment. Throughout the course of history, most novel treatments have met resistance from potential benefactors, it is thus important to show that the potential benefits are highly superior than the risks for novel treatments to be completely accepted by the population as a whole.

\section{Acknowledgment}

The authors would like to thank the Consejo Nacional de Investigaciones Científicas y Técnicas (CONICET), Agencia Nacional de Promoción Científica y Tecnológica (ANPCyT), Consejo de Investigaciones de la Universidad Nacional de Tucumán (CIUNT), the Centro Argentino Brasileño de Biotecnología (CABBIO), the Coordenação de Aperfeiçoamento de Pessoal de Nível Superior (CAPES), Fundação de Amparo à Pesquisa do Estado de Minas Gerais (FAPEMIG) and the Conselho Nacional de Desenvolvimento Científico e Tecnológico (CNPq) for their financial support.

\section{References}

Baumgart, D. C., \& Sandborn, W. J. (2007). Inflammatory bowel disease: clinical aspects and established and evolving therapies. The Lancet 369, pp.1641-1657. 
Bolotin, A., Mauger, S., Malarme, K., Ehrlich, S. D., \& Sorokin, A. (1999). Low-redundancy sequencing of the entire Lactococcus lactis IL1403 genome. A Van Leeuw J Microb 76(1-4), pp.27-76.

Braat, H., Rottiers, P., Hommes, D. W., Huyghebaert, N., Remaut, E., Remon, J. P., van Deventer, S. J., Neirynck, S., Peppelenbosch, M. P., \& Steidler, L. (2006). A phase I trial with transgenic bacteria expressing interleukin-10 in Crohn's disease. Clin Gastroenterol Hepatol 4(6), pp.754-759.

Campieri, M., Rizzello, F., Venturi, A., Poggioli, G., Ugolini, F., Helwig, U., Amasini, C., Romboli, E., \& Gionchetti, P. (2000). Combination of antibiotic and probiotic treatment is efficacious in prophylaxis of post-operative recurrence of Crohn's disease: a randomised controlled study v. mesalazine. Gastroenterology 118, pp.A4179.

Carroll, I. M., Andrus, J. M., Bruno-Barcena, J. M., Klaenhammer, T. R., Hassan, H. M., \& Threadgill, D. S. (2007). Anti-inflammatory properties of Lactobacillus gasseri expressing manganese superoxide dismutase using the interleukin 10-deficient mouse model of colitis. Am J Physiol Gastrointest Liver Physiol 293(4), pp.G729-738.

Chaves, S., Perdigon, G., \& de Moreno de LeBlanc, A. (2011). Yoghurt consumption regulates the immune cells implicated in acute intestinal inflammation and prevents the recurrence of the inflammatory process in a mouse model. J Food Prot 74(5), pp.801-811.

de Moreno de LeBlanc, A., Chaves, S., \& Perdigon, G. (2009). Effect of yoghhurt on the cytokine profile using a murine model of intestinal inflammation. Eur J Inflam 7 (2), pp.97-109.

de Moreno de LeBlanc, A., del Carmen, S., Zurita-Turk, M., Santos Rochat, C., van de Guchte, M., Azevedo, V., Miyoshi, A., \& LeBlanc, J. G. (2011). Importance of IL-10 modulation by probiotic microorganisms in gastrointestinal inflammatory diseases. ISRN Gastroenterology 1(1), pp.1-10 doi:10.5402/2011/892971.

de Moreno de LeBlanc, A., LeBlanc, J. G., Perdigon, G., Miyoshi, A., Langella, P., Azevedo, V., \& Sesma, F. (2008). Oral administration of a catalase-producing Lactococcus lactis can prevent a chemically induced colon cancer in mice. J Med Microbiol 57(Pt 1), pp.100-105.

del Carmen, S., de Moreno de LeBlanc, A., Miyoshi, A., Santos Rochat, C., Azevedo, V., \& LeBlanc, J. G. (2011). Application of probiotics in the prevention and treatment of ulcerative colitis and other inflammatory bowel diseases. Ulcers 1(1), pp.1-13. doi:10.1155/2011/841651

Djordjevic, G. M., \& Klaenhammer, T. R. (1998). Inducible gene expression systems in Lactococcus lactis. Mol Biotechnol 9(2), pp.127-139.

Elson, C. O., \& Weaver, C. T. (2003) Experimental mouse models of inflammatory bowel disease: new insights into pathogenic mechanisms in: Inflammatory bowel disease. From bench to bedside, S. R. Targan, F. Shanahan, and L. C. Karp, 2nd Edition ed, pp.67-95. Springer Science+Business Media, Inc., New York.

FAO/WHO (2001). Report of a Joint FAO/WHO Expert Consultation on Evaluation of Health and Nutritional Properties of Probiotics in Food Including Powder Milk with Live Lactic Acid Bacteria.

Flynn, S., van Sinderen, D., \& Thornton, G. (2002). Characterization of the genetic locus responsible for the production of ABP-118, a novel bacteriocin produced by the probiotic bacterium Lactobacillus salivarius subsp. salivarius UCC118. Microbiology 148, pp.973-984. 
Frossard, C. P., Steidler, L., \& Eigenmann, P. A. (2007). Oral administration of an IL-10secreting Lactococcus lactis strain prevents food-induced IgE sensitization. J Allergy Clin Immunol 119(4), pp.952-959.

Galdeano, C. M., de Moreno de LeBlanc, A., Vinderola, G., Bonet, M. E., \& Perdigon, G. (2007). Proposed model: mechanisms of immunomodulation induced by probiotic bacteria. Clin Vaccine Immunol 14(5), pp.485-492.

Garcia-Lafuente, A., Antolin, M., Guarner, F., Crespo, E., \& Malagelada, J. R. (2001). Modulation of colonic barrier function by the composition of the commensal flora in the rat. Gut 48(4), pp.503.

Guimaraes, V., Innocentin, S., Chatel, J. M., Lefevre, F., Langella, P., Azevedo, V., \& Miyoshi, A. (2009). A new plasmid vector for DNA delivery using lactococci. Genet Vaccines Ther 7, pp.4.

Han, W., Mercenier, A., Ait-Belgnaoui, A., Pavan, S., Lamine, F., van, S., II, Kleerebezem, M., Salvador-Cartier, C., Hisbergues, M., Bueno, L., Theodorou, V., \& Fioramonti, J. (2006). Improvement of an experimental colitis in rats by lactic acid bacteria producing superoxide dismutase. Inflamm Bowel Dis 12(11), pp.1044-1052.

Head, K. A., \& Jurenka, J. S. (2003). Inflammatory bowel disease Part 1: ulcerative colitis-pathophysiology and conventional and alternative treatment options. Altern Med Rev 8(3), pp.247-283.

Hilsden, R. J., Meddings, J. B., \& Sutherland, L. R. (1996). Intestinal permeability changes in response to acetylsalicylic acid in relatives of patients with Crohn's disease. Gastroenterology 110(5), pp.1395-1403.

Huyghebaert, N., Vermeire, A., Neirynck, S., Steidler, L., Remaut, E., \& Remon, J. P. (2005a). Development of an enteric-coated formulation containing freeze-dried, viable recombinant Lactococcus lactis for the ileal mucosal delivery of human interleukin10. Eur J Pharm Biopharm 60(3), pp.349-359.

Huyghebaert, N., Vermeire, A., Neirynck, S., Steidler, L., Remaut, E., \& Remon, J. P. (2005b). Evaluation of extrusion/spheronisation, layering and compaction for the preparation of an oral, multi-particulate formulation of viable, hIL-10 producing Lactococcus lactis. Eur J Pharm Biopharm 59(1), pp.9-15.

Isolauri, E., Salminen, S., \& Ouwehand, A. C. (2004). Microbial-gut interactions in health and disease. Probiotics. Best Pract Res Clin Gastroenterol 18(2), pp.299-313.

Klaenhammer, T. (1988). Bacteriocins of lactic acid bacteria. Biochimie 70, pp.337-349.

Kruidenier, L., van Meeteren, M. E., Kuiper, I., Jaarsma, D., Lamers, C. B., Zijlstra, F. J., \& Verspaget, H. W. (2003). Attenuated mild colonic inflammation and improved survival from severe DSS-colitis of transgenic Cu/Zn-SOD mice. Free Radic Biol Med 34(6), pp.753-765.

Kuipers, O. P., Beerthuyzen, M. M., de Ruyter, P. G., Luesink, E. J., \& de Vos, W. M. (1995). Autoregulation of nisin biosynthesis in Lactococcus lactis by signal transduction. $J$ Biol Chem 270(45), pp.27299-27304.

Kullisaar, T., Zilmer, M., \& Mikelsaar, M. (2002). Two antioxidative lactobacilli strains as promising probiotics. Int J Food Microbiol 72, pp.215-224.

LeBlanc, J. G., de Moreno de LeBlanc, A., Perdigón, G., Miyoshi, A., Rochat, T., BermudezHumaran, L., Langella, P., Sesma, F., \& Azevedo, V. (2008). Anti-inflammatory properties of Lactic Acid Bacteria: Current knowledge, applications and prospects. Anti-Infective Agents in Medicinal Chemistry 7 (3), pp.148-154.

LeBlanc, J. G., del Carmen, S., Miyoshi, A., Azevedo, V., Sesma, F., Langella, P., BermudezHumaran, L., Watterlot, L., Perdigon, G., \& de Moreno de LeBlanc, A. (2011). Use of 
superoxide dismutase and catalase expressing lactic acid bacteria to attenuate TNBS induced Crohn's disease in mice. Journal of Biotechnology. 151(3), pp.287-293.

Loos, M., Remaut, E., Rottiers, P., \& De Creus, A. (2009). Genetically engineered Lactococcus lactis secreting murine IL-10 modulates the functions of bone marrow-derived dendritic cells in the presence of LPS. Scand J Immunol 69(2), pp.130-139.

Mack, D. R., Michail, S., Wei, S., McDougall, L., \& Hollingsworth, M. A. (1999). Probiotics inhibit enteropathogenic E. coliadherence in vitro by inducing intestinal mucin gene expression. American Journal of Physiology-Gastrointestinal and Liver Physiology 276(4), pp.G941.

Madsen, K., Cornish, A., Soper, P., McKaigney, C., Jijon, H., Yachimec, C., Doyle, J., Jewell, L., \& De Simone, C. (2001). Probiotic bacteria enhance murine and human intestinal epithelial barrier function. Gastroenterology 121(3), pp.580-591.

Madsen, K. L., Doyle, J. S., Jewell, L. D., Tavernini, M. M., \& Fedorak, R. N. (1999). Lactobacillus species prevents colitis in interleukin 10 gene-deficient mice. Gastroenterology 116, pp.1107-1114.

Makarova, K., Slesarev, A., Wolf, Y., Sorokin, A., Mirkin, B., Koonin, E., Pavlov, A., Pavlova, N., Karamychev, V., Polouchine, N., Shakhova, V., Grigoriev, I., Lou, Y., Rohksar, D., Lucas, S., Huang, K., Goodstein, D. M., Hawkins, T., Plengvidhya, V., Welker, D., Hughes, J., Goh, Y., Benson, A., Baldwin, K., Lee, J. H., Diaz-Muniz, I., Dosti, B., Smeianov, V., Wechter, W., Barabote, R., Lorca, G., Altermann, E., Barrangou, R., Ganesan, B., Xie, Y., Rawsthorne, H., Tamir, D., Parker, C., Breidt, F., Broadbent, J., Hutkins, R., O'Sullivan, D., Steele, J., Unlu, G., Saier, M., Klaenhammer, T., Richardson, P., Kozyavkin, S., Weimer, B., \& Mills, D. (2006). Comparative genomics of the lactic acid bacteria. Proc Natl Acad Sci U S A 103(42), pp.1561115616.

Mallon, P., McKay, D., Kirk, S., \& Gardiner, K. (2007). Probiotics for induction of remission in ulcerative colitis. Cochrane Database Syst Rev (4), pp.CD005573.

Mao, Y., Nobaek, S., Kasravi, B., Adawi, D., Stenram, U., Molin, G., \& Jeppsson, B. (1996). The effects of Lactobacillus strains and oat fiber on methotrexate-induced enterocolitis in rats. Gastroenterology 111(2), pp.334-344.

Marinho, F. A., Pacifico, L. G., Miyoshi, A., Azevedo, V., Le Loir, Y., Guimaraes, V. D., Langella, P., Cassali, G. D., Fonseca, C. T., \& Oliveira, S. C. (2010). An intranasal administration of Lactococcus lactis strains expressing recombinant interleukin-10 modulates acute allergic airway inflammation in a murine model. Clin Exp Allergy 40(10), pp.1541-1551.

Meddings, J. (2008). The significance of the gut barrier in disease. Gut 57(4), pp.438.

Mierau, I., \& Kleerebezem, M. (2005). 10 years of the nisin-controlled gene expression system (NICE) in Lactococcus lactis. Appl. Microbiol. Biotechnol. 68(6), pp.705-717.

Miyoshi, A., Bermudez-Humaran, L., Pacheco de Azevedo, M., Langella, P., \& Azevedo, V. (2010) Lactic Acid Bacteria as Live Vectors: Heterologous Protein Production and Delivery Systems in: Biotechnology of Lactic Acid Bacteria Novel Applications, F. Mozzi, R. Raya, and G. Vignolo, pp.161-176. Blackwell Publishing, Ames, Iowa, USA.

Miyoshi, A., Jamet, E., Commissaire, J., Renault, P., Langella, P., \& Azevedo, V. (2004). A xylose-inducible expression system for Lactococcus lactis. FEMS Microbiol Lett 239(2), pp.205-212.

NCBI. 2011. Microbial genomes (http://www.ncbi.nlm.nih.gov/genomes/MICROBES/microbial_taxtree.html). 
Ng, S. C., Hart, A. L., Kamm, M. A., Stagg, A. J., \& Knight, S. C. (2009). Mechanisms of action of probiotics: recent advances. Inflammatory bowel diseases 15(2), pp.300-310.

Nouaille, S., Ribeiro, L. A., Miyoshi, A., Pontes, D., Le Loir, Y., Oliveira, S. C., Langella, P., \& Azevedo, V. (2003). Heterologous protein production and delivery systems for Lactococcus lactis. Genet Mol Res 2(1), pp.102-111.

O'Sullivan, D. J. (2001). Screening of intestinal microflora for effective probiotic bacteria. J Agric Food Chem 49(4), pp.1751-1760.

O'Mahony, L., Feeney, M., O'Halloran, S., Murphy, L., Kiely, B., Fitzgibbon, J., Lee, G., O'Sullivan, G., Shanahan, F., \& Collins, J. K. (2001). Probiotic impact on microbial flora, inflammation and tumour development in IL-10 knockout mice. Aliment Pharmacol Ther 15, pp.1219-1225.

Otte, J., \& Podolsky, D. ( 2004). Functional modulation of enterocytes by Gram-positive and Gram-negative microorganisms. Am J Physiol Gastrointest Liver Physiol 286, pp.G613-G626.

Ouwehand, A. C., Salminen, S., \& Isolauri, E. (2002). Probiotics: an overview of beneficial effects. Antonie Van Leeuwenhoek 82(1-4), pp.279-289.

Price, A. B. (1992) Inflammatory Bowel Disease in: Oxford Textbook of Pathology, J. O. D. McGee, P. G. Isaacson, and N. A. Wright, pp.1234-1254. Oxford University Press, Oxford. UK.

Rea, M., Clayton, E., \& O'Connor, P. (2007). Antimicrobial activity of lacticin 3,147 against clinical Clostridium difficile strains. J Med Microbiol 56, pp.940 -946.

Rochat, T., Bermudez-Humaran, L., Gratadoux, J. J., Fourage, C., Hoebler, C., Corthier, G., \& Langella, P. (2007). Anti-inflammatory effects of Lactobacillus casei BL23 producing or not a manganese-dependant catalase on DSS-induced colitis in mice. Microb Cell Fact 6(22), pp.1-10.

Rochat, T., Gratadoux, J. J., Gruss, A., Corthier, G., Maguin, E., Langella, P., \& van de Guchte, M. (2006). Production of a heterologous nonheme catalase by Lactobacillus casei: an efficient tool for removal of $\mathrm{H} 2 \mathrm{O} 2$ and protection of Lactobacillus bulgaricus from oxidative stress in milk. Appl Environ Microbiol 72(8), pp.5143-5149.

Rochat, T., Miyoshi, A., Gratadoux, J. J., Duwat, P., Sourice, S., Azevedo, V., \& Langella, P. (2005). High-level resistance to oxidative stress in Lactococcus lactis conferred by Bacillus subtilis catalase KatE. Microbiology 151(Pt 9), pp.3011-3018.

Sanders, J. W., Leenhouts, K. J., Haandrikman, A. J., Venema, G., \& Kok, J. (1995). Stress response in Lactococcus lactis: cloning, expression analysis, and mutation of the lactococcal superoxide dismutase gene. J Bacteriol 177(18), pp.5254-5260.

Schmitz, H., Barmeyer, C., Fromm, M. L., Runkel, N., Foss, H. D., Bentzel, C. J., Riecken, E. O., \& Schulzke, J. D. (1999). Altered tight junction structure contributes to the impaired epithelial barrier function in ulcerative colitis. Gastroenterology 116(2), pp.301-309.

Schotte, L., Steidler, L., Vandekerckhove, J., \& Remaut, E. (2000). Secretion of biologically active murine interleukin-10 by Lactococcus lactis. Enzyme and Microbial Technology 27, pp.761-765.

Schultz, M., Munro, K., Tannock, G. W., Melchner, I., Göttl, C., Schwietz, H., Schölmerich, J., \& Rath, H. C. (2004). Effects of feeding a probiotic preparation (SIM) containing inulin on the severity of colitis and on the composition of the intestinal microflora in HLA-B27 transgenic rats. Clin Diagn Lab Immunol 11, pp.581-587.

Segui, J., Gironella, M., Sans, M., Granell, S., Gil, F., Gimeno, M., Coronel, P., Pique, J. M., \& Panes, J. (2004). Superoxide dismutase ameliorates TNBS-induced colitis by 
reducing oxidative stress, adhesion molecule expression, and leukocyte recruitment into the inflamed intestine. J Leukoc Biol 76(3), pp.537-544.

Spyropoulos, B., Misiakos, E., Fotiadis, C., \& Stoidis, C. (2010). Antioxidant Properties of Probiotics and Their Protective Effects in the Pathogenesis of Radiation-Induced Enteritis and Colitis. Digestive Diseases and Sciences, pp.1-10.

Steidler, L., Hans, W., Schotte, L., Neirynck, S., Obermeier, F., Falk, W., Fiers, W., \& Remaut, E. (2000). Treatment of murine colitis by Lactococcus lactis secreting interleukin-10. Science 289(5483), pp.1352-1355.

Steidler, L., Neirynck, S., Huyghebaert, N., Snoeck, V., Vermeire, A., Goddeeris, B., Cox, E., Remon, J. P., \& Remaut, E. (2003). Biological containment of genetically modified Lactococcus lactis for intestinal delivery of human interleukin 10. Nat Biotechnol 21(7), pp.785-789.

Sybesma, W., Hugenholtz, J., de Vos, W. M., \& Smid, E. J. (2006). Safe use of genetically modified lactic acid bacteria in food. Bridging the gap between consumers, green groups, and industry. Elect. J. Biotechnol. 9(4), pp.424-448.

Szatrowski, T. P., \& Nathan, C. F. (1991). Production of large amounts of hydrogen peroxide by human tumor cells. Cancer Res 51(3), pp.794-798.

Termont, S., Vandenbroucke, K., Iserentant, D., Neirynck, S., Steidler, L., Remaut, E., \& Rottiers, P. (2006). Intracellular accumulation of trehalose protects Lactococcus lactis from freeze-drying damage and bile toxicity and increases gastric acid resistance. Appl Environ Microbiol 72(12), pp.7694-7700.

Tournoy, K. G., Kips, J. C., \& Pauwels, R. A. (2000). Endogenous interleukin-10 suppresses allergen-induced airway inflammation and nonspecific airway responsiveness. Clin Exp Allergy 30(6), pp.775-783.

Tursi, A., Brandimarte, G., Papa, A., Giglio, A., Elisei, W., Giorgetti, G. M., Forti, G., Morini, S., Hassan, C., Pistoia, M. A., Modeo, M. E., Rodino, S., D'Amico, T., Sebkova, L., Sacca, N., Di Giulio, E., Luzza, F., Imeneo, M., Larussa, T., Di Rosa, S., Annese, V., Danese, S., \& Gasbarrini, A. (2010). Treatment of relapsing mild-to-moderate ulcerative colitis with the probiotic VSL\#3 as adjunctive to a standard pharmaceutical treatment: a double-blind, randomized, placebo-controlled study. Am J Gastroenterol 105(10), pp.2218-2227.

Venturi, A., Gionchetti, P., Rizzello, F., Johansson, R., Zucconi, E., Brigidi, P., Matteuzzi, D., \& Campieri, M. (1999). Impact on the composition of the faecal flora by a new probiotic preparation: preliminary data on maintenance treatment of patients with ulcerative colitis. Aliment Pharmacol Ther 13(8), pp.1103-1108.

Waeytens, A., Ferdinande, L., Neirynck, S., Rottiers, P., De Vos, M., Steidler, L., \& Cuvelier, C. A. (2008). Paracellular entry of interleukin-10 producing Lactococcus lactis in inflamed intestinal mucosa in mice. Inflamm Bowel Dis 14(4), pp.471-479.

Watterlot, L., Rochat, T., Sokol, H., Cherbuy, C., Bouloufa, I., Lefevre, F., Gratadoux, J. J., Honvo-Hueto, E., Chilmonczyk, S., Blugeon, S., Corthier, G., Langella, P., \& Bermudez-Humaran, L. G. (2010). Intragastric administration of a superoxide dismutase-producing recombinant Lactobacillus casei BL23 strain attenuates DSS colitis in mice. Int J Food Microbiol 144(1), pp.35-41.

Weiner, H. L., Gonnella, P. A., Slavin, A., \& Maron, R. (1997). Oral tolerance: cytokine milieu in the gut and modulation of tolerance by cytokines. Res Immunol 148(8-9), pp.528533. 